\title{
Ti Particles Dispersed Ti-Based Metallic Glass Matrix Composite Prepared by Spark Plasma Sintering
}

\author{
Shengli Zhu ${ }^{1,2,3, *}$, Guoqiang Xie ${ }^{1}$, Fengxiang Qin ${ }^{1}$, Xinmin Wang ${ }^{1}$ and Takao Hanawa ${ }^{4}$ \\ ${ }^{1}$ Institute for Materials Research, Tohoku University, Sendai 980-8577, Japan \\ ${ }^{2}$ School of Materials Science and Engineering, Tianjin University, Tianjin, 300072, China \\ ${ }^{3}$ Tianjin Key Laboratory of Composite and Functional Materials, Tianjin, 300072, China \\ ${ }^{4}$ Institute of Biomaterials and Bioengineering, Tokyo Medical and Dental University, Tokyo 101-0062, Japan
}

Using spark plasma sintering (SPS) process, Ti particles dispersed $\mathrm{Ti}_{40} \mathrm{Zr}_{10} \mathrm{Cu}_{36} \mathrm{Pd}_{14}$ metallic glass (MG) matrix composites were fabricated. The X-ray diffractometry (XRD), differential scanning calorimetry (DSC), scanning electron microscopy (SEM) and compressive tests were used for examining the microstructure and properties of the composites. The experiment results showed that the as-sintered composite exhibited mainly dense structure. The Ti-based MG and pure Ti particles were coalesced together closely. There was no distinct gap or interface between the Ti-based MG matrix and pure Ti particles. No crystallization was observed in the Ti-based glassy matrix. The addition of Ti particles improved the plasticity of the Ti-based MG composite, while had no significant influence on the thermal stability of MG matrix. [doi:10.2320/matertrans.MF201311]

(Received January 30, 2013; Accepted April 8, 2013; Published May 17, 2013)

Keywords: metallic glass, composite, spark plasma sintering, plasticity

\section{Introduction}

Bulk metallic glasses (BMGs) possess an amorphous structure without long-range order, endowing them particular unique properties such as excellent corrosion resistance, large elastic limit $(\sim 2 \%)$, low elastic modulus, high strength as well as good formability in the supercooled liquid region. ${ }^{1-4)}$ The unique mechanical properties of BMGs can meet the requirements of biomedical applications, such as high recovery of strain $(\geq 2 \%)$ and low Young's modulus which can reduce the "stress-shielding" effect. ${ }^{5)}$ Excellent corrosion resistance of BMGs makes them favor of utilization in human body which is a complex corrosive system. Ti-based BMGs are expected to be applied as good biomaterials due to combining the advantages of both BMG and Ti alloy. Some works have been carried out about the fabrication of Tibased BMGs. ${ }^{6-10)}$ We have developed the Ti-Zr-Cu-Pd(-Sn) BMGs which exhibited high glass-forming ability (GFA), high strength and low Young's modulus. ${ }^{11-14)}$ However, the lack of plasticity is a drawback which hinders the wide applications of BMGs. BMGs exhibit very limited plasticity, generally less than $2 \%$ before fracturing under compressing loads. Numerous efforts have been made to improve the plasticity in BMGs. Forming composite with plastic particles addition is considered as an effective approach.

Recently, MG matrix composites attracted much attention due to their improved characteristics. ${ }^{15-23)}$ As a novel rapid sintering technique, the spark plasma sintering (SPS) can fabricate the high quality sintering materials within a short time by controlling some process parameters. The sintering can be carried out at a lower temperature and in a shorter time as compared with the conventional sintering process. Consequently, the SPS is adapted for sintering the materials which are required to suppress crystallization and grain growth, such as MGs. ${ }^{22-24)}$

*Corresponding author, E-mail: slzhu@imr.tohoku.ac.jp
In the present work, metallic $\mathrm{Ti}$ particles with good biocompatibility and plasticity were chosen as second phase to improve the properties through the formation of Ti-based MG matrix composites using the SPS technique.

\section{Materials and Methods}

$\mathrm{Ti}_{40} \mathrm{Zr}_{10} \mathrm{Cu}_{36} \mathrm{Pd}_{14} \mathrm{MG}$ was chosen as a base material because of its high glass-forming ability. The ingots of the alloy were prepared by arc-melting the mixture of pure elements with purities above $99.9 \%$ in an Ar atmosphere. The alloy composition represents the nominal atomic percentage of the mixture. The $\mathrm{Ti}_{40} \mathrm{Zr}_{10} \mathrm{Cu}_{36} \mathrm{Pd}_{14} \mathrm{MG}$ powders were prepared by a high pressure argon gas atomization method, and then classified by a conventional sieving method. The powders with size less than $63 \mu \mathrm{m}$ were used for the subsequent experiments. The $\mathrm{Ti}_{40} \mathrm{Zr}_{10} \mathrm{Cu}_{36} \mathrm{Pd}_{14} \mathrm{MG}$ powders were mixed with Ti particles (mean size of $75 \mu \mathrm{m}$ ) for $24 \mathrm{~h}$ using a V-type rotating mixer. The sintering was carried out in a vacuum using a SPS system (Model: SPS-3.20 MK-IV) at $643 \mathrm{~K}$ under a sintering pressure of $600 \mathrm{MPa}$. The heating rates were $50 \mathrm{~K} / \mathrm{min}$ (from room temperature to $543 \mathrm{~K}$ ), $10 \mathrm{~K} / \mathrm{min}$ (from $543 \mathrm{~K}$ to $623 \mathrm{~K}$ ) and $5 \mathrm{~K} / \mathrm{min}$ (from $623 \mathrm{~K}$ to $643 \mathrm{~K}$ ). The holding time at $643 \mathrm{~K}$ was $10 \mathrm{~min}$. The sintered samples had a cylindrical shape with a diameter of $15 \mathrm{~mm}$ and a height of about $6 \mathrm{~mm}$.

X-ray diffraction (XRD) with a monochromatic $\mathrm{Cu} \mathrm{K} \alpha$ radiation was used to examine the structure of the powders and the sintered samples. Thermal stability was evaluated by differential scanning calorimetry (DSC) at a heating rate of $0.67 \mathrm{~K} / \mathrm{s}$. The microstructure of the sintered samples was examined by scanning electron microscopy (SEM) coupled with an X-ray energy dispersive spectrometer (EDS). The densities of the composites were measured by the Archimedes method. Compression tests were conducted using a conventional mechanical testing machine under an initial strain rate of $5 \times 10^{-4} \mathrm{~s}^{-1}$. The samples with a 

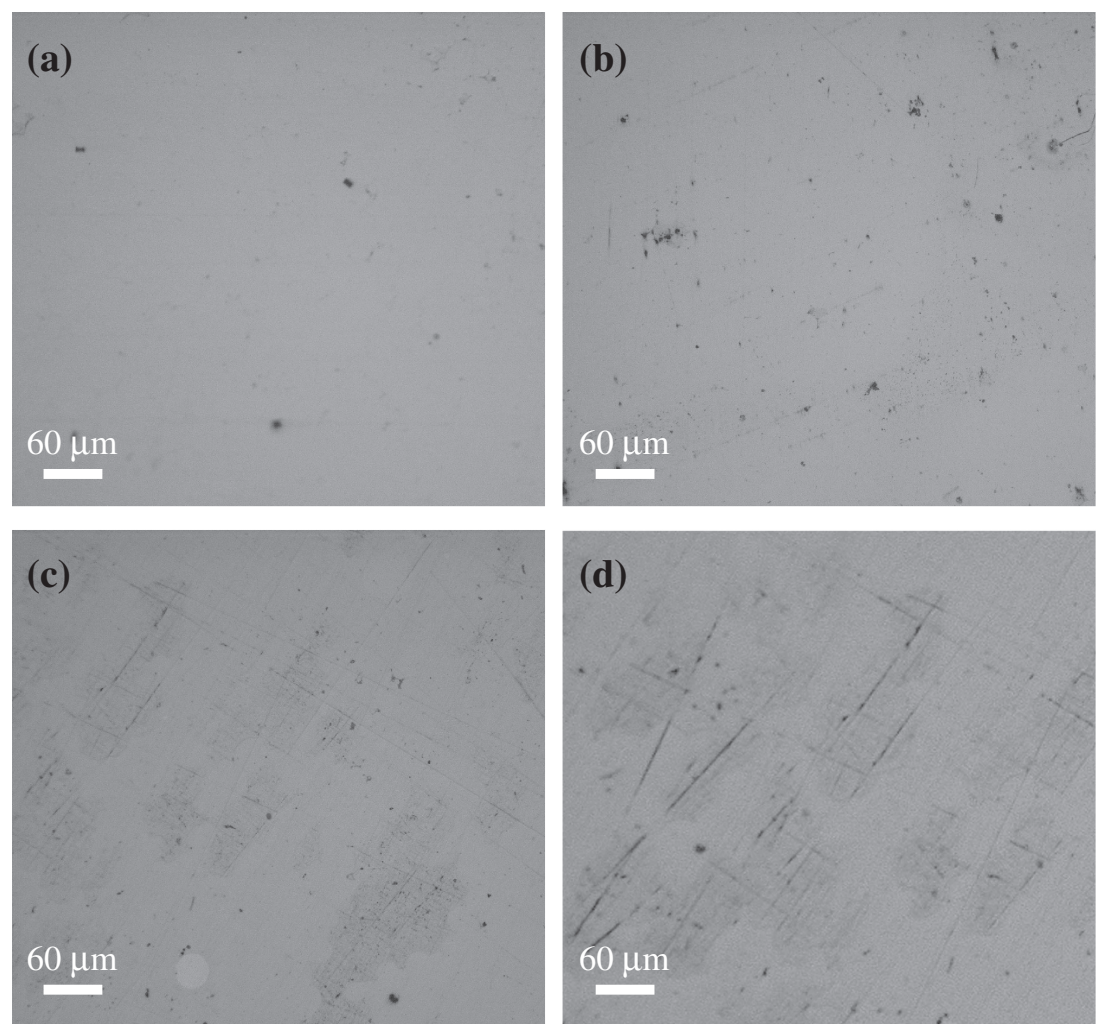

Fig. 1 Optical microscopy images of as-sintered samples with various Ti particle contents (mass\%): (a) $0 \%$; (b) $5 \%$; (c) $10 \%$; (d) $20 \%$.

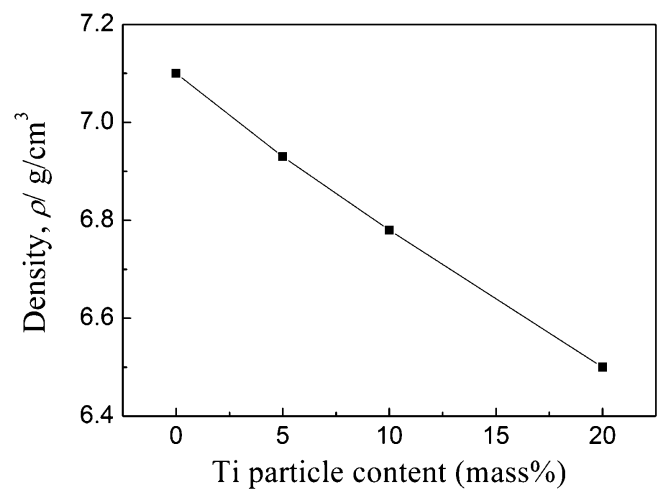

Fig. 2 Density of the composites with various $\mathrm{Ti}$ particle contents (mass\%).

rectangular shape of $2.5 \mathrm{~mm}$ in width, $2.5 \mathrm{~mm}$ in thickness and $5 \mathrm{~mm}$ in height were used for compressive test.

\section{Results and Discussion}

Figure 1 shows the optical microscopy images of assintered samples with various $\mathrm{Ti}$ particle additions. All samples exhibit mainly dense structure with several pores. No obvious interface between particles is observed. For the samples with Ti particle additions, there are some shadows which indicate exist of various phases. With Ti particle content increasing, the areas of shadows increase. Figure 2 shows the density of the composite with various Ti particle additions. The density of the sample without Ti addition is $7.1 \mathrm{~g} / \mathrm{cm}^{3}$, which is slightly lower than that of the as-casted BMG sample with the same composition (about $7.2 \mathrm{~g} / \mathrm{cm}^{3}$ ).

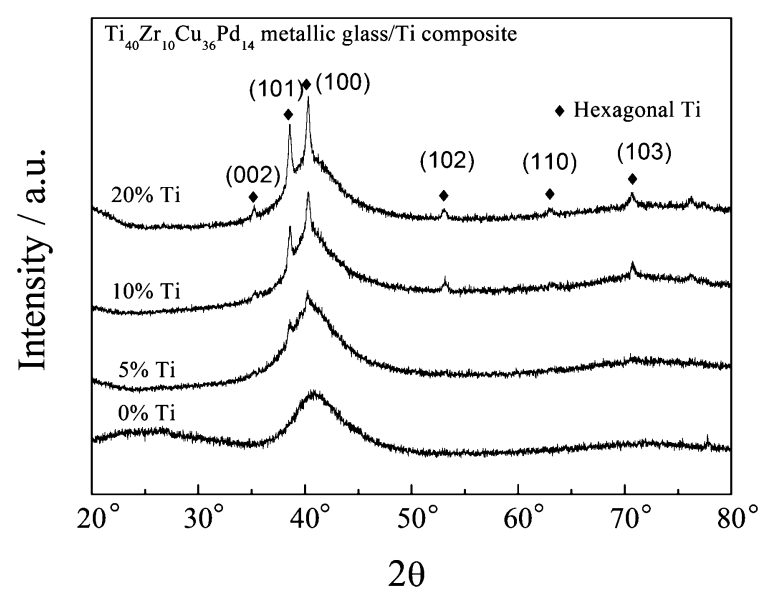

Fig. 3 XRD patterns of as-sintered samples with various Ti particle contents (mass\%).

With increasing $\mathrm{Ti}$ particle content, the density decreases linearly. Figure 3 shows the XRD patterns of as-sintered samples with various $\mathrm{Ti}$ particle additions. The sample without Ti particle addition exhibits a broad halo corresponding to the MG matrix. Several diffraction peaks are superimposed over the broad halo for the samples with $\mathrm{Ti}$ particle additions. These peaks were indexed as hexagonal $\mathrm{Ti}$ phase, and the indices of lattice plane were also marked in the Fig. 3. With the content of Ti particle increasing, the diffraction peaks become stronger. Figure 4 shows the DSC curves of the as-sintered samples with various $\mathrm{Ti}$ particle additions. There is no distinct difference between the DSC curves. All samples exhibit similar characters, such as $T_{\mathrm{g}}, T_{\mathrm{x}}$, curve's shape and the crystallization events. The $T_{\mathrm{g}}$ and $T_{\mathrm{x}}$ 


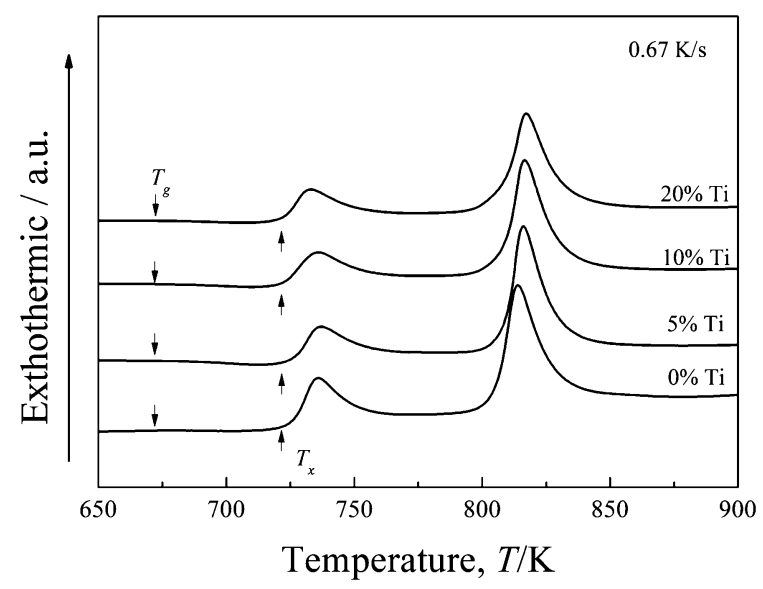

Fig. 4 DSC curves of as-sintered samples with various Ti particle contents (mass\%).

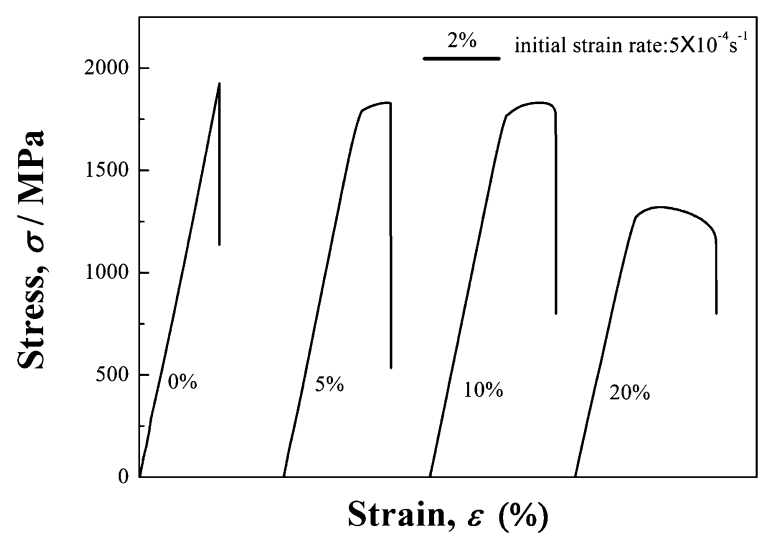

Fig. 5 Stress-strain curves of as-sintered samples with various Ti particle contents (mass\%).

were characterized as 672 and $723 \mathrm{~K}$ according to the DSC curves. However, the crystallization peaks become weak with increasing Ti particles content.

Figure 5 shows the compressive stress-strain curves. The sample without Ti particles addition exhibits high strength about $1950 \mathrm{MPa}$, and no plastic elongation. For the samples with 5 and 10 mass $\%$ Ti particle additions, the strength decreases slightly, while the plastic elongation increases. For the sample with 20 mass $\%$ Ti particles addition, the strength decreases to about $1350 \mathrm{MPa}$, while the plastic elongation increases to $2.1 \%$. All samples with $\mathrm{Ti}$ particles addition exhibit a work-hardening procedure due to the plastic deformation of pure Ti particles.

Figure 6(a) shows the fracture surface of the sample with 10 mass $\%$ Ti particles addition. The fracture surface features two distinct zones. Zone (I) is evenly distributed vein-like structure, which is a classical $\mathrm{MG}$ fracture surface. At zone (II) there exists lots of toughness stripes, which were formed by the fracture of Ti particle. EDS was used to examine the compositions of various zones. Figures 6(b) and 6(c) are the EDS patterns taken from zone (I) and (II), respectively. The test areas were marked with rectangles. Zone (I) is composed of $\mathrm{Ti}, \mathrm{Zr}, \mathrm{Cu}$ and $\mathrm{Pd}$ elements, indicating a Ti-based MG powder. While zone (II) is only compose of $\mathrm{Ti}$ with a small amount of $\mathrm{O}$, indicating a $\mathrm{Ti}$
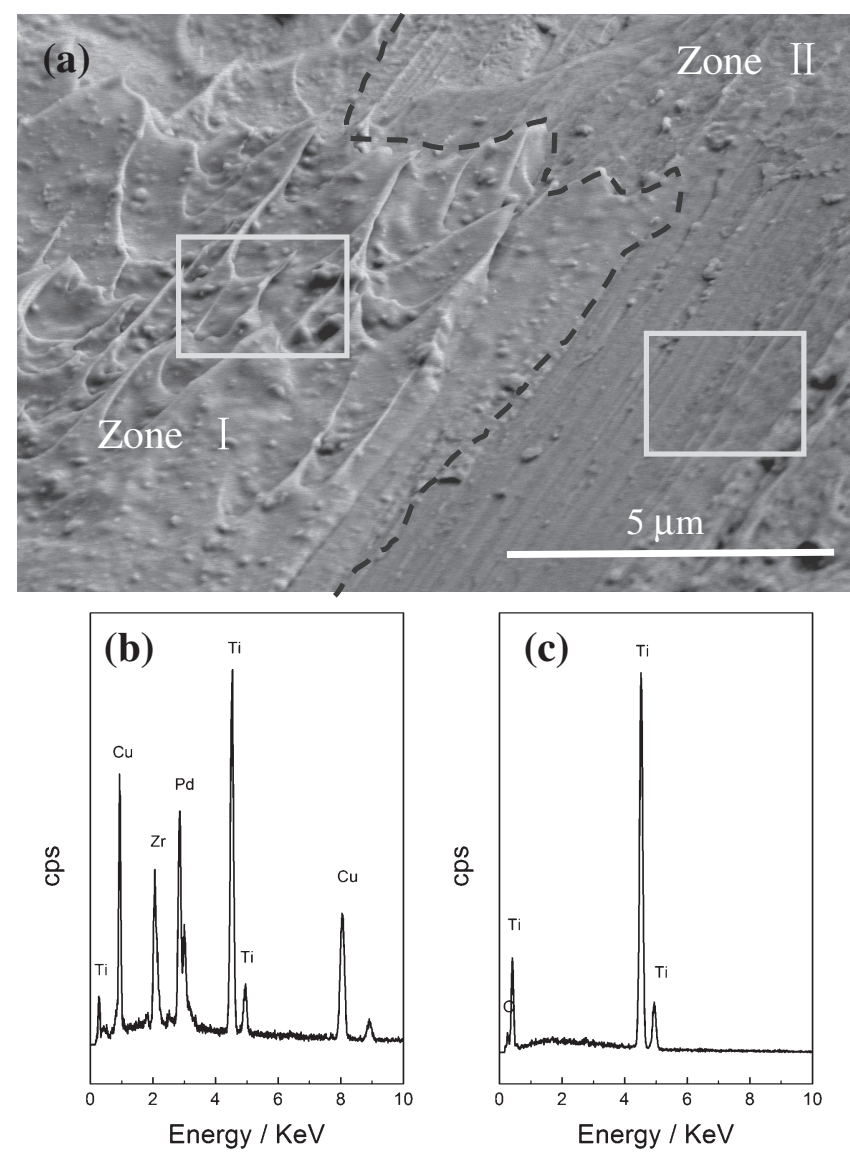

Fig. 6 Fracture surface image (a) and EDS patterns (b), (c) of as-sintered sample with 10 mass\% Ti particle addition: (b) and (c) are corresponding to zone (I) and (II), respectively.

particle. The small amount of $\mathrm{O}$ should come from the $\mathrm{Ti}$ oxides formed during the SPS process. One can see that the Ti-based MG powder and pure Ti particle are coalesced together closely. No distinct gap or interface is observed between the Ti-based MG and pure Ti particles.

The SPS process is an electrical sintering technique which applies a pulse DC voltage. The pulse electric current directly flows through the sintered powder materials in the SPS process, and a very high heating efficiency is offered. The SPS includes various phenomena: ${ }^{22-24)}$ (a) electrical breakdown of surface oxide film and removal of contaminated layer on particle surface by spark generation and sputtering effect; (b) destruction of surface oxide film and neck formation between powder particles; (c) focused current and Joule heat at the neck; and (d) enhanced migration of atom or ion by the difference in temperature between neck and particle core as well as by electrical field, and neck growth. The phenomena provide advantages which cannot be obtained using the conventional sintering process. At the beginning of SPS process, the initial pressure is applied on the mixing particles and plays the role on neck formation. The neck formation is due to the geometric amplification of the pressure on the interparticle point contacts. At this stage the pulsed current is applied and a current path is established in metallic particles. The current is forced to choose the path of least resistance. Metallic particles would be locally melted at the contact interface 
due to the instantaneous Joule effect. The heat is transferred immediately and diffused to whole particles so that the intergranular bonding portion is quickly cooled. This favors the sintering of MG materials or metastable phase materials. $^{23)}$ In the present work, the sintering temperature is $643 \mathrm{~K}$, which is far lower than the crystallization temperature $(723 \mathrm{~K})$. Therefore, the crystallization during sintering would not occur. Our previous work synthesized Ti-based MG matrix composite with hydroxyapatite (HA) addition using the SPS method. The addition of HA, which had lower heat and electric conductivity, enhanced the "constriction resistance" as a result of decreasing the contact area of $\mathrm{MG}$ powders, furthermore, increases the local Joule heat. Also the existence of HA reduces the dissipation of Joule heat since HA has lower heat conductivity. Hence, the MG powders were partially crystallized. ${ }^{23)}$ In the present work, Ti particles were chosen as improve phase. Above mentioned partial crystallization was avoided completely. Both $\mathrm{Ti}_{40} \mathrm{Zr}_{10^{-}}$ $\mathrm{Cu}_{36} \mathrm{Pd}_{14}$ alloy and pure $\mathrm{Ti}$ has high oxidation reaction at high temperatures. The inadequate vacuum during melting probably made some impurities, such as surface oxide film. This would suppress the atomic diffusion in the neck formation stage. The SPS process is expected to solve this problem because of its unique characters, as mentioned above.

The initial pressure during SPS process is so high (much higher than the yield strength of pure $\mathrm{Ti}$ ) that the plastic deformation of pure $\mathrm{Ti}$ particles would occur. In addition, $\mathrm{Ti}_{40} \mathrm{Zr}_{10} \mathrm{Cu}_{36} \mathrm{Pd}_{14} \mathrm{MG}$ powders would also have a strong deformation during the sintering process due to the viscous flow of MG at the high temperature above $0.7 T_{\mathrm{g}}{ }^{23)}$ These deformations cause the reduction of the pores in the sintered samples. The bonding at the interface between MG matrix and Ti particles can be improved through the formation of the protrusion by both plastic deformation of $\mathrm{Ti}$ particles and viscous flow deformation of MG powders.

According to Fig. 5, we know that the plasticity was improved due to the addition of Ti particles. Shear banding in the MG matrix is a main factor to influence the plastic deformation in $\mathrm{MG}$ and $\mathrm{MG}$ composites. In the present composites, shear bands would be arrested by the MG/Ti interfaces and cannot travel freely or run away. The traveling distance, i.e., mean free path, of shear bands is affected by the presence of Ti particles and limited by the interparticle spacing of Ti particles. This interparticle free spacing is an effective index for the mean free path of shear banding. The smaller mean free path results in higher plasticity. ${ }^{24-26)}$ Hence, the Ti particles addition improves the plasticity of the composite.

The pure Ti has low density, excellent corrosion resistance and good biocompatibility. The Ti-based MG exhibits unique mechanical property, such as high strength and low Young's modulus. Combing with the advantages of MG and pure Ti, the Ti-based MG matrix composite is expected to be good candidate for applications of biomaterials.

\section{Conclusions}

We successfully synthesized the Ti-based MG matrix composite with Ti particles addition using SPS process. The as-sintered composite exhibited mainly dense structure. No crystallization was observed in the Ti-based MG matrix. The addition of Ti particles had no significant influence on the $T_{\mathrm{g}}$ and $T_{\mathrm{x}}$ of MG matrix. After SPS, the Ti-based MG powders and pure Ti particles were coalesced together closely. There was no distinct gap or interface between the Ti-based MG matrix and pure $\mathrm{Ti}$ particles. The addition of $\mathrm{Ti}$ particles improved the plasticity of the Ti-based MG matrix composite.

\section{REFERENCES}

1) A. Inoue: Acta Mater. 48 (2000) 279-306.

2) A. L. Greer: Science 267 (1995) 1947-1953.

3) W. H. Wang, C. Dong and C. H. Shek: Mater. Sci. Eng. R 44 (2004) 45-89.

4) W. L. Johnson: MRS Bull. 24 (1999) 42-56.

5) S. L. Zhu, X. J. Yang, D. H. Fu, L. Y. Zhang, C. Y. Li and Z. D. Cui: Mater. Sci. Eng. A 408 (2005) 264-268.

6) T. Zhang, A. Inoue and T. Masumoto: Mater. Sci. Eng. A 181-182 (1994) 1423-1426

7) A. Inoue, N. Nishiyama, K. Amiya, T. Zhang and T. Masumoto: Mater. Lett. 19 (1994) 131-135.

8) T. Zhang and A. Inoue: Mater. Trans. 39 (1998) 1001-1006.

9) H. Men, S. J. Pang, A. Inoue and T. Zhang: Mater. Trans. 46 (2005) 2218-2220.

10) Y. C. Kim, W. T. Kim and D. H. Kim: Mater. Sci. Eng. A 375-377 (2004) 127-135.

11) S. L. Zhu, X. M. Wang, F. X. Qin and A. Inoue: Mater. Sci. Eng. A 459 (2007) 233-237.

12) S. L. Zhu, X. M. Wang, F. X. Qin, M. Yoshimura and A. Inoue: Mater. Trans. 48 (2007) 2445-2448.

13) S. L. Zhu, X. M. Wang and A. Inoue: Intermetallics 16 (2008) 10311035.

14) S. L. Zhu, G. Q. Xie, F. X. Qin, X. M. Wang and A. Inoue: Mater. Trans. 53 (2012) 500-503.

15) H. M. Fu, H. Wang, H. F. Zhang and Z. Q. Hu: Scr. Mater. 54 (2006) 1961-1966.

16) S. Y. Lee, B. Clausen, E. Üstündag, H. Choi-Yim, C. Can Aydiner and M. A. M. Bourke: Mater. Sci. Eng. A 399 (2005) 128-133.

17) Y. F. Sun, C. H. Shek, S. K. Guan, B. C. Wei and J. Y. Geng: Mater. Sci. Eng. A 435-436 (2006) 132-138.

18) S. L. Zhu, X. M. Wang, G. Q. Xie, F. X. Qin, M. Yoshimura and A. Inoue: Scr. Mater. 58 (2008) 287-290.

19) L. C. Zhang, F. Jiang, D. H. Zhang, L. He, J. Sun, J. T. Fan and Z. F. Zhang: Adv. Eng. Mater. 10 (2008) 943-950.

20) K. B. Kim, J. Das, F. Baier, M. B. Tang, W. H. Wang and J. Eckert: Appl. Phys. Lett. 88 (2006) 051911.

21) G. Kumar, T. Ohkubo, T. Mukai and K. Hono: Scr. Mater. 57 (2007) $173-176$.

22) G. Q. Xie, D. V. Louzguine-Luzgin, H. Kimura and A. Inoue: Intermetallics 18 (2010) 851-858.

23) S. L. Zhu, X. M. Wang, F. X. Qin, M. Yoshimura and A. Inoue: Mater. Trans. 49 (2008) 502-505.

24) G. Q. Xie, W. Zhang, D. V. Louzguine-Luzgin, H. Kimura and A. Inoue: Scr. Mater. 55 (2006) 687-690.

25) J. S. C. Jang, J. B. Li, S. L. Lee, Y. S. Chang, S. R. Jian, J. C. Huang and T. G. Nieh: Intermetallics 30 (2012) 25-29.

26) J. B. Li, J. S. C. Jang, C. Li, S. R. Jian, P. H. Tsai, J. D. Hwang, J. C. Huang and T. G. Nieh: Mater. Sci. Eng. A 551 (2012) 249-254. 